\title{
A Presynaptic Gain Control Mechanism among Sensory Neurons of a Locust Leg Proprioceptor
}

\author{
Malcolm Burrows and Thomas Matheson \\ Department of Zoology, University of Cambridge, Cambridge CB2 3EJ, England
}

The chordotonal organ at the femorotibial joint of a locust hind leg monitors extension and flexion movements of the tibia. During evoked or imposed movements of this joint the central terminals of afferent neurons from the chordotonal organ receive depolarizing, inhibitory synaptic inputs. The afferent spikes are therefore superimposed on these depolarizing IPSPS, which are generated indirectly by other afferents from the same organ that respond to the same movement. Each afferent spikes preferentially to particular features of a joint movement, and its synaptic input is typically greatest at the joint position or during the movement that generates its best response. Afferents that respond to only one direction of movement receive synaptic inputs either during movements in both directions, or only during movements in their preferred direction. Phasic velocity-sensitive afferents receive either phasic inputs during movements, or tonic inputs at new sustained joint positions, or both. The spikes of tonic position-sensitive afferents are superimposed on synaptic inputs that are dependent on joint position. The synaptic inputs sum but do not themselves evoke antidromic spikes in the afferent terminals. They reduce the amplitude of orthodromic afferent spikes by 12$28 \%$, and this is accompanied by a reduction of up to $50 \%$ in the amplitude of monosynaptic EPSPs evoked by an afferent in postsynaptic leg motor neurons. These interactions suggest that a local gain control mechanism operates between the afferents of this proprioceptor. Thus, the effectiveness of the output synapses of an individual afferent is regulated by the network action of other chordotonal afferents that respond to the same movement.

[Key words: presynaptic inhibition, gain control, chordotonal organ, locomotion, reflex, motor neurons]

Synaptic potentials are common in the central terminals of afferent neurons in both vertebrates (Frank and Fuortes, 1957; Schmidt, 1971; Rudomin, 1990a,b) and invertebrates (Kennedy et al., 1974; Blagburn and Sattelle, 1987; Small et al., 1989; Cattaert et al., 1992). Many of these potentials are generated by neurons that release GABA (Eccles et al., 1963; Davidoff, 1972; Nicoll and Alger, 1979; Cattaert et al., 1992). Their effect is often to depolarize the terminals, reduce the amplitude of the

\footnotetext{
Received Mar. 30, 1993; revised June 22, 1993; accepted June 30, 1993.

This work was supported by a grant from the Human Frontier Science Program to M.B. We thank F. Kuenzi, P. Newland, A. Norman, and D. Parker for commenting on earlier drafts of the manuscript.

Correspondence should be addressed to Professor Malcolm Burrows, Department of Zoology, University of Cambridge, Downing Street, Cambridge CB2 3EJ, England.

Copyright $(\mathcal{1} 1994$ Society for Neuroscience $0270-6474 / 94 / 140272-11 \$ 05.00 / 0$
}

presynaptic spikes and thereby the effectiveness of transmission to postsynaptic neurons. The potentials are generated by sets of interneurons activated centrally during locomotion, or by inputs from the same or different sensory modalities. Thus, cutaneous afferents may be inhibited by surrounding cutaneous afferents (Janig et al., 1968), and Ia afferents by Ia afferents from other muscles (Rudomin et al., 1983; Rudomin, 1990a). Ib afferents can be inhibited by cutaneous afferents and by other Ib afferents (Rudomin et al., 1986; Jimenez et al., 1988; Rudomin, 1990a). During fictive locomotion, both cutaneous and muscle afferents receive a centrally generated, rhythmic input that depolarizes them and can evoke antidromic spikes (Gossard et al., 1990, 1991). During voluntary locomotion, this input will interact with the feedback generated by the movement itself and can be one factor that modulates the effectiveness of sensory transmission in a phase-dependent manner (Skorupski and Sillar, 1986; Gossard et al., 1990). During voluntary movements in humans, the inhibition of Ia afferents of muscles that are contracting is reduced, while that of antagonistic muscles is increased (Hultborn et al., 1987). The net effect would be to increase the excitation of motor neurons of the contracting muscles and prevent activation of other motor neurons.

Despite this wealth of information about the inhibition of afferents in vertebrates, it is often difficult to determine the underlying connectivity, and therefore to know what role it might play in normal movements; for example, do afferents from the same muscle interact with each other? In some invertebrates, however, individual sensory neurons can be recorded intracellularly from an alert animal while sensory neurons from the same receptors are activated during voluntary or imposed movements. Movements of the joints of arthropod limbs are monitored by a range of proprioceptors. In the locust, a prominent proprioceptor at the femorotibial joint of a hind leg is a chordotonal organ (Usherwood et al., 1968) containing approximately 90 sensory neurons (Matheson and Field, 1990). Flexion or extension movements of the tibia about the femur stretch and relax the distal attachment points of the organ (Field, 1991; Shelton et al., 1992), exciting sensory neurons that code position, velocity, or acceleration, separately or in various combinations (Hofmann and Koch, 1985; Hofmann et al., 1985; Zill, 1985a; Matheson, 1990, 1992a,b). The afferent neurons synapse in parallel with flexor and extensor motor neurons, spiking and nonspiking local interneurons, and intersegmental interneurons (Burrows, 1987; Burrows et al., 1988; Laurent and Burrows, 1988). This pattern of connections underlies interjoint and intrajoint reflexes of a hind leg (Field and Rind, 1981; Field and Burrows, 1982). These reflexes are variable and under some conditions can reverse in sign (Bässler, 1976; Bässler et al., 1986; Zill and Jepson-Innes, 1990). One mechanism underlying this 
variability involves a population of intersegmental interneurons that affects the gain of local reflexes by influencing nonspiking interneurons that are part of the local circuits controlling limb movements (Laurent and Burrows, 1989a,b).

A second mechanism could involve the synaptic inputs that are made onto the terminals of the afferents themselves by an unidentified population of interneurons. These are depolarizing IPSPs that appear to be mediated by GABA and that can decrease the excitability of the afferent terminals (Burrows and Laurent, 1993). Here we show that many of these synaptic inputs to the central terminals of afferent neurons from the metathoracic femorotibial chordotonal organ are caused indirectly, but reliably, by other afferent neurons from the same organ. These inputs reduce the effectiveness of the output synapses that the afferents make with motor neurons. The timing of the inputs from the other chordotonal organ afferents suggests that they act as a local gain control mechanism that adjusts the output synapses of individual afferents. This would mean that the effectiveness of each individual afferent is regulated by the pooled responses of the other active chordotonal afferents.

\section{Materials and Methods}

Adult male and female locusts, Schistocerca gregaria (Forskål), from our crowded colony were used in all experiments. Locusts were restrained ventral side upward using Plasticine so that the femur of the left hind leg was horizontal with its anterior surface uppermost (see Fig. $2 A$ ). In some experiments the femorotibial joint was fixed at an angle of $60^{\circ}$, but in others it was, like those of the other legs, able to move freely. The apodeme of the metathoracic femoral chordotonal organ was exposed in the distal femur (see Fig. $2 B$ ) and grasped with fine forceps distal to the point where fine strands insert upon it ("unloading strand," Field, 1991: "guy-rope fibrils," Shelton et al., 1992), and then cut distally. The forceps were attached to a vibrator (Ling Dynamic, type 101), the movements of which were controlled by a microcomputer or by an analog ramp gencrator (Matheson and Ditz, 1991). The flcxor strand (see Fig. $2 B$ ) of the chordotonal organ remained attached to the apodeme of the flexor tibiae muscle. Linear movements of the chordotonal apodeme mimicked angular extension or flexion movements of the tibia, in the range of those normally used during walking $\left(0-120^{\circ}\right)$. Any possible distortions of the afferent responses by these imposed movements did not appear to be significant, because the same responses could also be produced by moving the tibia with the chordotonal organ intact [see Field and Burrows, 1982, for the relationship between movements of the apodeme and the femorotibial angle]. Extracellular recordings of the spikes of sensory neurons from the femoral chordotonal organ were made with hook electrodes on $\mathrm{N} 5 \mathrm{~B} 1$ in the femur just proximal to the organ (see Fig. $2 B$ ). These electrodes were also used for stimulation. In some experiments, N5B1 was also recorded or stimulated electrically by hook electrodes placed distal to the chordotonal organ (sec Fig. 2B).

The thorax was opened and the mesothoracic and metathoracic ganglia were stabilized on a wax-coated steel platform. The ganglionic sheath was treated with a $0.1 \%(\mathrm{w} / \mathrm{v})$ solution of protease (Sigma type XIV) for 40-120 sec before recording began. Intracellular recordings were made using electrodes filled with $2 \mathrm{~m}$ potassium acetate $(50-80 \mathrm{M} \Omega$ ) or, when individual neurons were to be stained, with hexammine cobaltic chloride (Brogan and Pitman, 1981). Recordings were made with either an Axoclamp $2 \mathrm{~A}$ (Axon Instruments) or a home-built amplifier with a frequency cutoff at $5 \mathrm{kHz}$. The axons of sensory neurons from the femoral chordotonal organ were impaled in N5 where it meets the metathoracic ganglion (see Fig. $1 A$ ), or in the neuropil close to the entry point of N5. In N5 there are some 10,000 axons, but recordings suggest that the approximately 90 axons of sensory neurons from the chordotonal organ are bundled together in an anteroventral region. As they leave the organ itself, the axons have diameters ranging from 0.3 to 5.1 $\mu \mathrm{m}$ (Matheson and Field, 1990). We assume that our recordings are from the larger axons, but they nevertheless still represent a wide spectrum of response properties. The afferents were identified, first, by their specific responses to controlled movements of the chordotonal apodeme; second, by correlating the spike recorded intracellularly in N5 with one recorded extracellularly and simultaneously in N5Bl close to
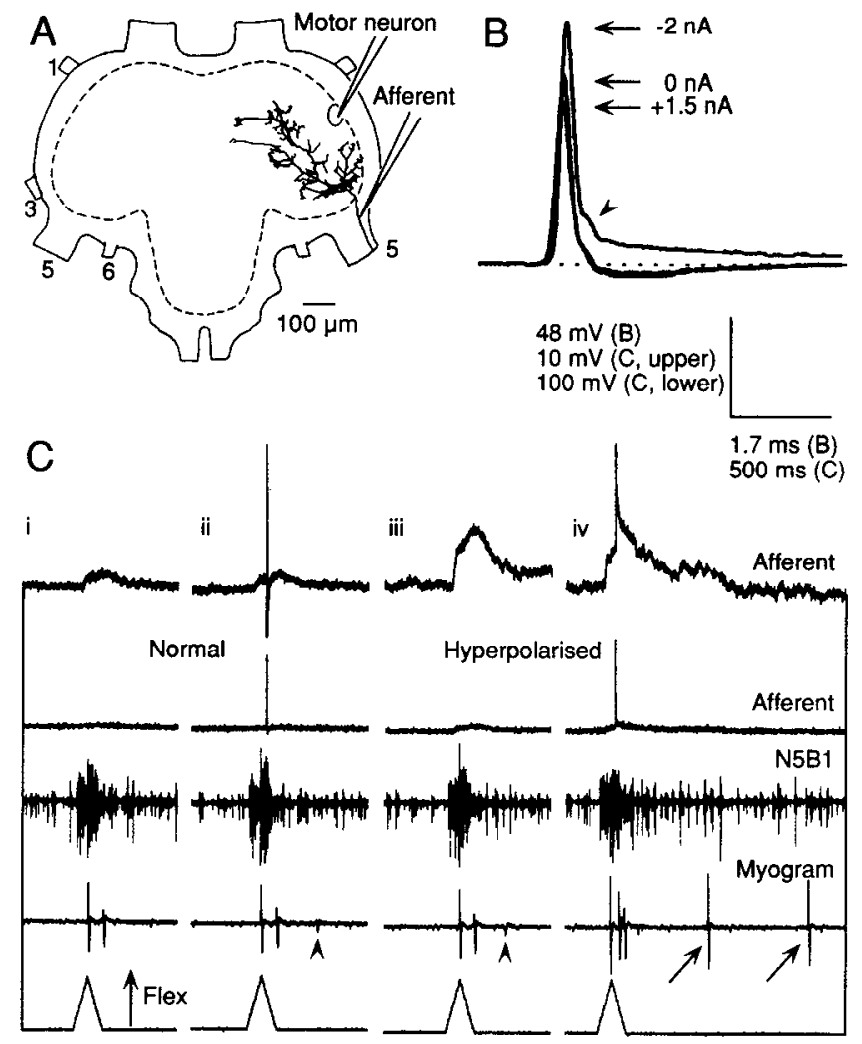

Figure 1. Spikes and synaptic potentials in chordotonal afferents. $A$. Drawing of the metathoracic ganglion to show where recordings were made from the axons of chordotonal afferents and from the cell bodies of leg motor neurons. The ganglion is viewed dorsally, with nerves 1 , 3,5 , and 6 numbered, and the boundary of the neuropil indicated with a dashed line. An individual chordotonal afferent stained with cobalt is drawn. $B$, Spike shapes at different membrane potentials of an afferent. At its normal membrane potential of $-69 \mathrm{mV}(0 \mathrm{nA})$, the spikes evoked by electrical stimulation of N5B1 were approximately $90 \mathrm{mV}$ in amplitude, and therefore overshot zero. Each spike was followed by a hyperpolarization. Injection of depolarizing current into the afferent $(+1.5 \mathrm{nA})$ decreased the spike height. Injection of hyperpolarizing current increased the spike height and width, and revealed a prolonged depolarization augmented by synaptic inputs (arrowhead). The spikes have been aligned to a common baseline. $C$. Imposed movements of the chordotonal organ apodeme (bottom trace) evoked spikes and synaptic potentials in an afferent (high gain on top trace, with peaks of spikes not shown, and lower gain on second trace to show the full spike amplitude), $i$ and $i i$, The afferent was at its normal resting potential. The first movement $(i)$ evoked only a synaptic input, whereas the second (ii) evoked a spike that was superimposed on a synaptic input. iii and $i v$, The afferent was hyperpolarized by $2 \mathrm{nA}$ to emphasize the synaptic input caused by a repetition of these two movements. The response of all the chordotonal organ afferents was monitored in N5B1 and the activity of the flexor and extensor tibiae motcr neurons in a myogram. The large spikes in the myogram were from the slow extensor tibiae motor neuron identified by the slow twitch contraction that they elicited in the muscle, and the slow movement of the tibia. Two of these (arrows in iv) did not cause inputs to the afferent. The changes in the amplitude of these spikes were caused by contractions of the muscle. Small spikes (arrowheads) were from flexor motor neurons.

the organ; third, by electrical stimulation of N5B1, an orthodromic spike could be evoked at the central recording sitc, but a stimulus applied to the nerve just distal to the chordotonal organ (see Fig. $2 B$ ) could not elicit spikes in the recorded afferents-this showed that the spikes originated at the organ; and fourth, by intracellular staining of afferents with these physiological properties, a characteristic pattern of central projections could be revealed (see Fig. 1A) (Burrows, 1987; Matheson, 1992a). Leg motor neurons were penetrated in their somata and identified using established criteria (Hoyle and Burrows, 1973). Recordings 
were stored on magnetic tape (Racal Store 7 DS) for later analysis and display on a Gould ES 1000 electrostatic recorder or a Gould TA 240 thermal array recorder. In Figures $1 C$ (top), $2 C, 3-6$, and $8 A, C$, the afferent spikes have been truncated so that a high gain could be used to display the synaptic inputs. A CED computer interface and software were used for signal averaging. The results presented here are based on 212 analyzed recordings from chordotonal organ afferents, and an approximately equal number of comparable recordings that were not analyzed in detail. Each afferent response type presented here was analyzed on at least 10 occasions.

\section{Results}

Synaptic potentials in an afferent result from spikes in other afferents from the same receptor

All stable recordings from chordotonal afferents made close to (Fig. $1 A$ ), or within, the metathoracic ganglion revealed spikes and depolarizing synaptic potentials in response to movements of the femorotibial joint, or to movements of the apodeme of the chordotonal organ itself. The spikes in these chordotonal organ afferents are generated close to their cell bodies in the organ, and are conducted into the CNS. By contrast, the synaptic potentials are generated in the terminal branches of the afferents within the neuropil of the CNS (Burrows and Laurent, 1993; Watson et al., 1993). The spikes recorded in axons as they entered the ganglion overshot zcro (Fig. $1 B$ ) from a normal resting potential of about $-72 \mathrm{mV}$ (Burrows and Laurent, 1993). The spikes were followed by a marked hyperpolarization, whether they occurred spontaneously or were evoked by electrical stimulation of $\mathrm{N} 5 \mathrm{~B} 1$ proximal to the chordotonal organ. If an afferent was depolarized with a steady current, the amplitude of the spike was reduced, but if it was hyperpolarized, the amplilude of the spike was increased and was now followed by a prolonged depolarization (Fig. $1 B$ ). This depolarization consisted of conductances associated with the spike itself, and those associated with synaptic potentials caused by other afferents excited by the electrical stimulus. Within the neuropil the spikes did not overshoot, suggesting that they were conducted decrementally to the synaptic release sites.

Synaptic potentials recorded in afferents at normal resting potential were at most a few millivolts in amplitude (Fig. $1 \mathrm{Ci}, \mathrm{ii}$ ). They are depolarizing IPSPs with a reversal potential that is only a few millivolts above normal resting potential (Burrows and Laurent, 1993). Hyperpolarization markedly increased the amplitude of these synaptic inputs (Fig. 1Ciil,iv). The synaptic potentials were evoked by the same controlled movements of the chordotonal apodeme that evoked spikes in the chordotonal afferents (Fig. 1C). For example, in one velocity-sensitive afferent the same movement that specifically excited chordotonal afferents sometimes led to a synaptic input alone (Fig. 1Ci,iii), or to a spike superimposed on this synaptic input (Fig. 1Cii,iv). At the same time, the movement reflexively excited the slow motor neuron innervating the extensor tibiae muscle, but these motor spikes occurred after the onset of the synaptic input to the afferent (Fig. 1C). When these motor spikes, or spikes in antagonistic flexor tibiae motor neurons, occurred after the movement (Fig. 1 Cii-iv) they were not associated with any additional synaptic input to the afferent. It would therefore appear that the synaptic inputs evoked by movement of the receptor apodeme resulted from activation of other chordotonal afferents excited by the same movement.

This inference was confirmed in eight experiments by electrical stimulation of the nerve (N5B1) that contains the chordotonal organ afferents. When N5B1 was stimulated proximal to the chordotonal organ (Fig. $2 B$ ), spikes followed by a marked depolarization were evoked in a chordotonal afferent recorded intracellularly near the metathoracic ganglion, where it was held hyperpolarized (Fig. 2C). When the stimulation voltage was reduced, the spike was no longer evoked, but instead synaptic potentials were now clear. If, however, electrical stimuli were then applied to the nerve distal to the chordotonal organ, which no longer contains chordotonal afferents (Fig. $2 B$ ), no synaptic inputs were evoked (Fig. $2 D$ ). This indicates that the synaptic inputs are caused by spikes in other chordotonal afferents, and not by spikes in afferents from more distal receptors with axons in N5B1. Further evidence that the synaptic inputs originated from other chordotonal afferents was sought by recording simultaneously from a pair of chordotonal afferents (Fig. 2E). When one of these afferents was induced to spike on rebound from a hyperpolarizing current, it consistently caused a PSP in the other afferent. Taken together, these results provide evidence that the synaptic inputs recorded in the central terminals of chordotonal afferents are caused by other chordotonal afferents. The synaptic potentials, however, did not result from direct interactions among the afferents themselves. In more than 50 recordings from pairs of afferents we found no evidence for direct connections. When spikes in one afferent evoked synaptic potentials in the other (Fig. $2 E$ ), the latency of $2.5 \mathrm{mscc}$ was too long for the connection to have been direct. The conclusion that the afferents do not interact directly is supported by pharmacological evidence indicating that the PSPs may be caused by GABA (Burrows and Laurent, 1993), a transmitter that is not used by insect mechanosensory neurons (see reviews by Callec, 1974; Sattelle and Breer, 1990). Instead, the PSPs appear to be caused by a reliable, short-latency and high-gain pathway that is activated by the afferent spikes and involves at least one layer of intervening interneurons (Fig. $2 F$ ).

Is the synaptic input related to the response properties of the afferent?

To understand the rules that determine when synaptic inputs to an afferent will occur as a result of spikes in other afferents from the same organ, afferents with a range of different response properties were recorded and the nature of their synaptic inputs was determined. Individual afferents code for the direction of movement, its velocity, acceleration, and the position of the joint (Hofmann and Koch, 1985; Hofmann et al., 1985; Zill, 1985a; Matheson, 1990). Figures 3-6 show selected afferents representing the features found in this array of at least 30 different response types.

\section{Phasic synaptic inputs}

Afferents that responded selectively to one direction of joint movement could receive a synaptic input during movements in both directions (Fig. 3). An extension-sensitive afferent received a continuous synaptic input during a slow flexion movement, and its spikes during extension were also superimposed on a synaptic input (Fig. $3 A$ ). This pattern of synaptic inputs also occurred during faster movements (Fig. $3 B$ ) and at all the velocities that were applied $\left(20-200^{\circ} \mathrm{sec}^{-1}\right)$. To test if the synaptic input to phasic afferents was related to the position of the joint from which a movement was made, the apodeme was moved in small steps over almost the full range of possible joint movements. Simultaneous intracellular recordings from an extensionsensitive and from a flexion-sensitive afferent during such movements again revealed synaptic inputs to both during both di- 

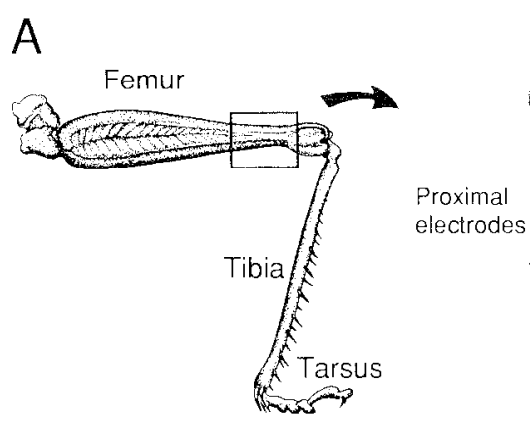

B
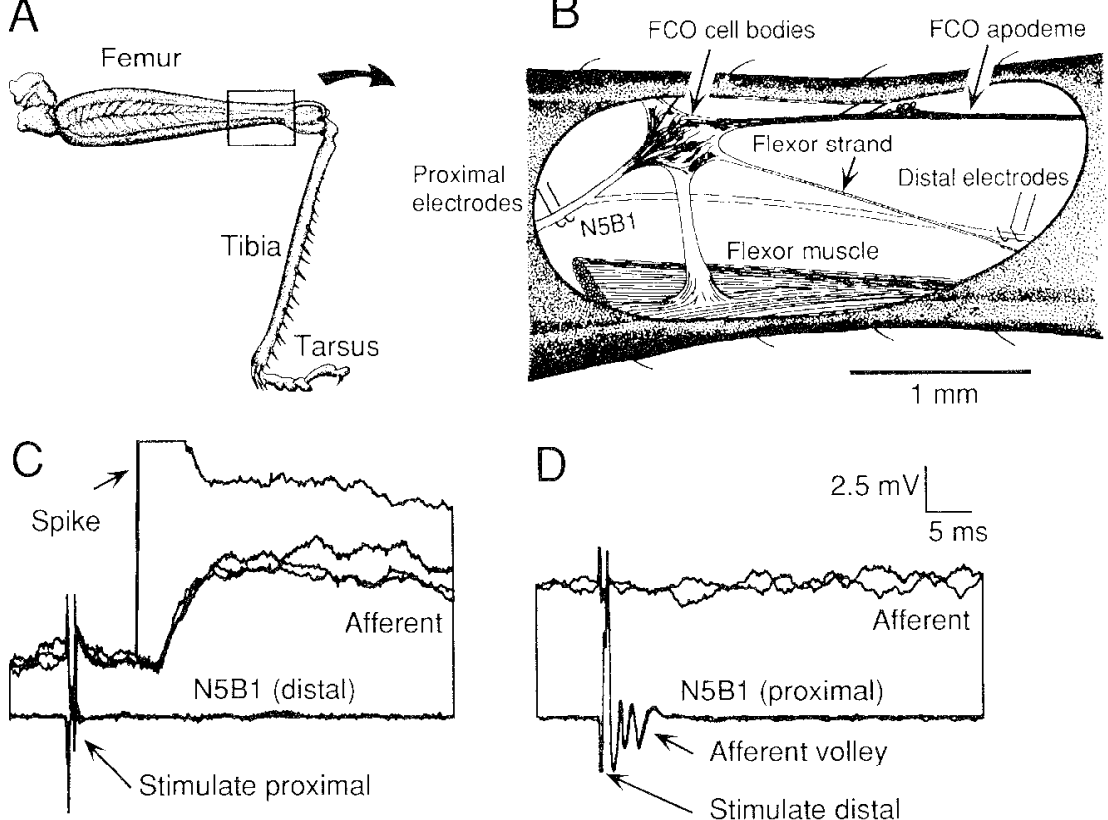

D
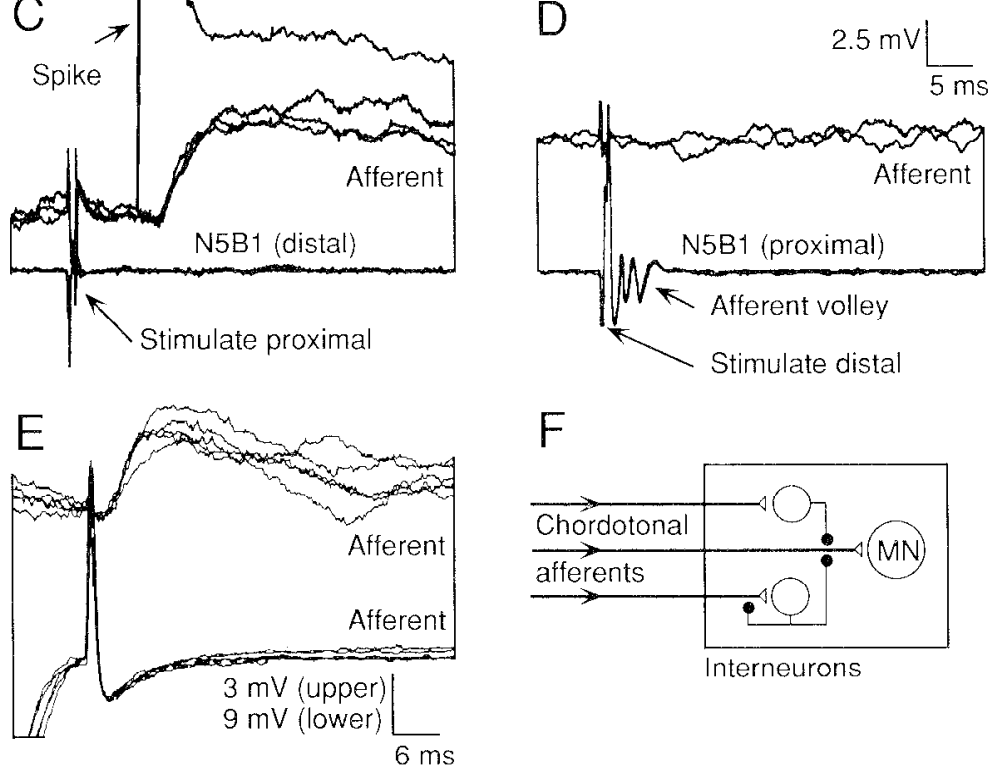

Figure 2. Identification of the source of the synaptic inputs. $A$, Drawing of a hind leg. $B$, The femorotibial joint of a hind leg opened from the anterior surface to show the chordotonal organ. Extracellular recording/stimulating sites on N5B1 are indicated. The proximal clectrodes can record and stimulate chordotonal organ afferents, but the distal electrodes can only record and stimulate the lew afferents in this continuation of $\mathrm{N} 5 \mathrm{~B} 1$ that innervate more distal receptors in the proximal tibia. $C$. Electrical stimulation at the proximal site cvoked a spike (peak not shown) in a chordotonal afferent recorded intracellularly close to the CNS. At lower voltages, repeated stimuli croked consistent depolarizing synaptic potentials. These stimuli did not excite axons that enter the distal branch of N5B1. as no evoked spikes were recorded by the distal electrodes. $D$. Flectrical stimulation at the distal site did not evoke spikes or synaptic inputs in this afferent, although the volley of spikes recorded by the proximal electrodes confirmed that many axons were stimulated. $E$. Simultaneous recordings from two chordotonal afferents. Spikes in one that were evoked by release from hyperpolarization consistently caused a synaptic potential with a latency of $2.5 \mathrm{msec}$ in the other afferent. $F$, The possible pathways that explain the central synaptic inputs to chordotonal afferents. The afferents make direct excitatory connections (triangles) onto motor neurons and interneurons (Burrows, 1987). Some unidentified interneurons must then make inhibitory connections (solid circles) back onto the central terminals of the afferents. rections of movement (Fig. 3C). At the more extended positions of the joint, a flexion movement evoked a few spikes on a small synaptic depolarization in the flexion-sensitive afferent, and a small depolarization in the cxtension-sensitive afferent. As the apodeme was stepped toward more flexed positions, the amplitude of the depolarization caused by the synaptic input, and the number of spikes in the flexion-sensitive afferent increased. The spike response was phasic but the synaptic depolarization was more sustained at each step to a new position. At the same time, the amplitude of the synaptic input increased in the extension-sensitive afferent. When the movement was reversed, the responses of the two afferents reversed; the extension-sensitive afferent spiked during each movement, but again these spikes were superimposed on a synaptic input, and the flexionsensitive afferent now received only a synaptic input. Thus, the amplitude of the synaptic inputs in both afferents was greatest for the directions of movement to which they responded with spikes, and increased progressively toward the more flexed positions where they gave their greatest spike responses. This means that the spikes were superimposed on synaptic inputs elicited by spikes of other afferents responding to the same movement.

Other extension-sensitive afferents received phasic synaptic inputs during flexion movements that were similar in amplitude over the whole range of joint positions (Fig. 4A). By contrast, the synaptic inputs during cxtension movements produced depolarizations of larger amplitudes, particularly at the more flexed positions. The spike response of this afferent was dependent on the velocity of extension movements (not shown), but the pattern of its synaptic inputs was independent of velocity. Therefore, whenever spikes occurred they were superimposed on a synaptic input that was dependent on the position of the joint.

Other flexion-sensitive afferents received a synaptic input of larger amplitude during extension movements than during flexion movements (Fig. 4B). Nevertheless, their spikes during flexion movements were still superimposed on a synaptic input. Some afferents that responded to both flexion and extension movements (acceleration receptors; Matheson, 1990) received a synaptic input during movements in only one direction (Fig. $4 C$ ). In the example shown, the synaptic input was greatest at the middle range of joint positions during flexion movements, whereas the spike response to higher velocity movements (not shown) was greatest at the more flexed positions. This means that the maximum synaptic input to a particular afferent is not always strictly related to its maximum spike response.

Afferents that respond to movement are most sensitive to particular velocities. To test whether the synaptic inputs to these afferents correlate with this sensitivity, different velocities of movement were imposed from a particular set position of the 
A

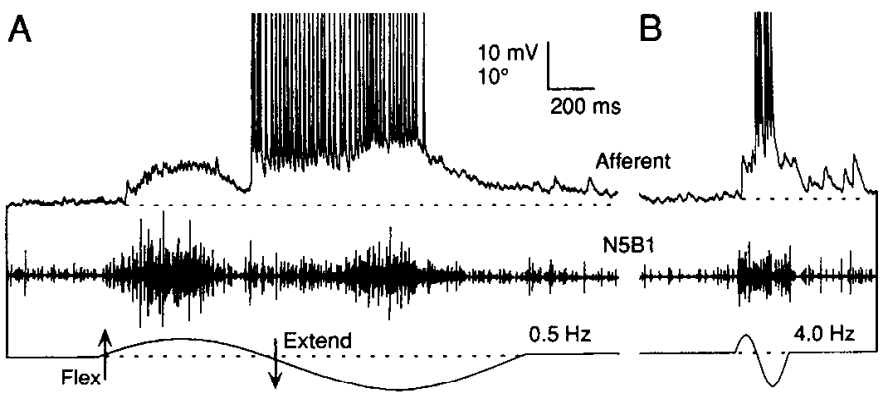

C

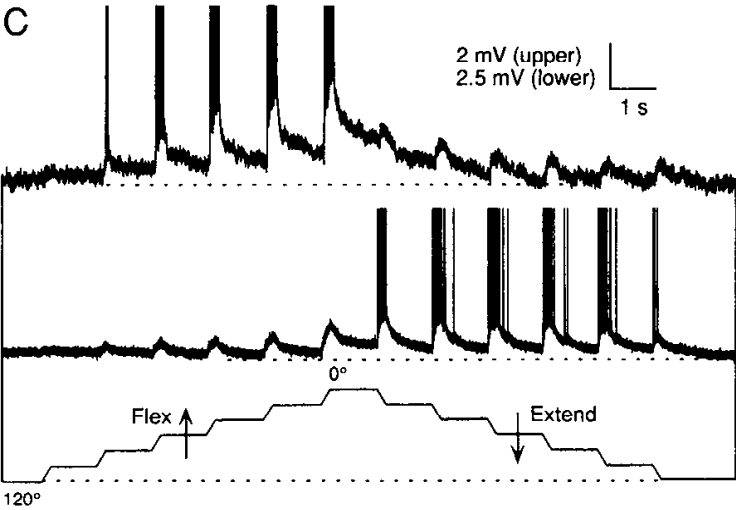

Figure 3. Synaptic inputs to phasic chordotonal afferents can occur during both extension and flexion movements of the tibia. $A$, An extension-sensitive afferent: flexion movements evoked PSPs, and extension movements evoked spikes that were superimposed on a depolarization. $B$, Faster movements evoked similar patterns of synaptic inputs but emphasized the synaptic input upon which the spikes were superimposed. $C$, Two afferents recorded simultaneously: one was extension sensitive, the other flexion sensitive, yet both received synaplic inputs during both directions of movement. The chordotonal apodeme was moved in steps corresponding to $20^{\circ}$ movements of the femorotibial joint from an initial extended position $\left(120^{\circ}\right)$ to a flexed position $\left(0^{\circ}\right)$ and back. Each afferent received synaptic inputs during movements in one direction, whereas movements in the other direction generated spikes superimposed on synaptic potentials. All three afferents were held hyperpolarized and the peaks of their spikes are not shown.

joint. An extension-sensitive afferent received a depolarizing synaptic input during low velocity movements (Fig. $5 A$ ). During these movements there were no spikes in flexor or extensor motor neurons to cause muscle contractions that could have excited any receptors in the leg. The synaptic inputs to the affercnt must therefore have been caused solely by other chordotonal afferents excited by the imposed movement. At higher frequencies of stimulation the synaptic inputs summated to give a sustained depolarization (Fig. 5B). This synaptic input again occurred in the absence of motor spikes (first cycle of movement), or preceded the motor spikes evoked by subsequent movements. When there was motor activity, the synaptic input was no greater than when there were no motor spikes, again suggesting that there was no feedback caused by muscle contraction. At still higher velocities, but within the normal range used during walking, the afferent produced spikes that were conveyed to the CNS, where they were superimposed on the large summed synaptic input generated by each movement (Fig. $5 C$ ). Therefore, even though this afferent spiked in response to movements only within a certain range of velocities, all velocities of movements tested evoked synaptic inputs. The spike response to a preferred stimulus was thus superimposed on a synaptic input.

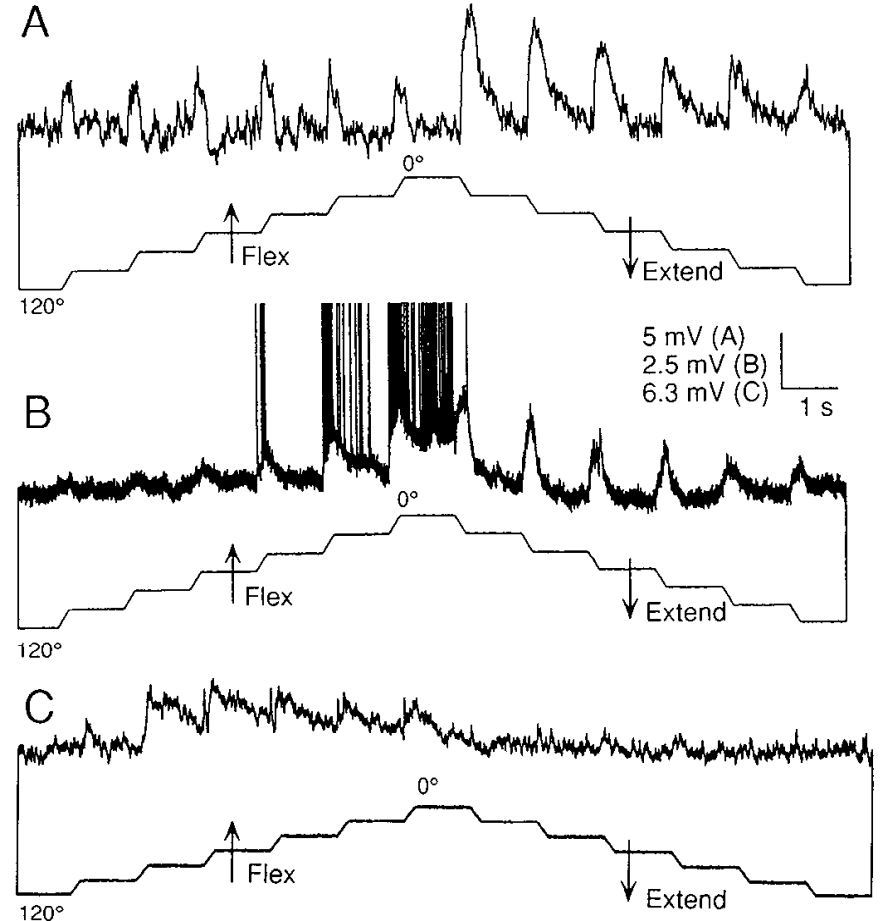

Figure 4. $A$, An afferent that coded for the velocity of extension received the greatest synaptic inputs during extension. These movements were not rapid enough to cause the afferent to spike, but still evoked a depolarizing synaptic input that was largest close to full flexion $\left(0^{\circ}\right) . B$, A flexion-sensitive afferent received the greatest synaptic inputs during extension. It spiked in response to flexion movements close to full flexion and received a phasic synaptic input during movements in both directions. The peaks of the spikes are not shown. $C$, An afferent that spiked phasically in response to both flexion and extension movements above the velocity shown here. Synaptic inputs occurred only during flexion movements, and were greatest at the middle of the range of joint movements. All three afferents were held hyperpolarized.

\section{Tonic synaptic inputs}

Both movement-sensitive and position-sensitive afferents could receive a tonic synaptic input that was dependent on the position of the joint (Fig. 6). An afferent that spiked phasically when the joint was flexed received a tonic synaptic input at the new joint position that adapted only slightly (Fig. $6 A$ ). This synaptic input was correlated with an increase of tonic activity in some other chordotonal afferents. By contrast, there were no sustained changes in flexor and extensor motor activity that could have contributed to the sustained synaptic input. The specificity of the synaptic input is illustrated when the apodeme was returned to its starting position. This movement caused increases in both the muscle activity and the overall chordotonal organ response, but a decrease in the synaptic input to the afferent. Similarly, an afferent that spiked tonically at one position of the joint repolarized only gradually during an extension movement, suggesting a gradual decline in a synaptic input (Fig. $6 B$ ). The rate of repolarization was correlated with the rate of the applied movement and with the rate of decline in the frequency of spikes in the other chordotonal afferents. When the joint was flexed again the afferent was depolarized by a synaptic input before the tonic spikes resumed (Fig. $6 B$ ). The tonic spikes were therefore always superimposed on a background of tonic synaptic inputs. Similarly, the amplitude of depolarizing synaptic inputs to phasic afferents could be related to the position of the joint. 

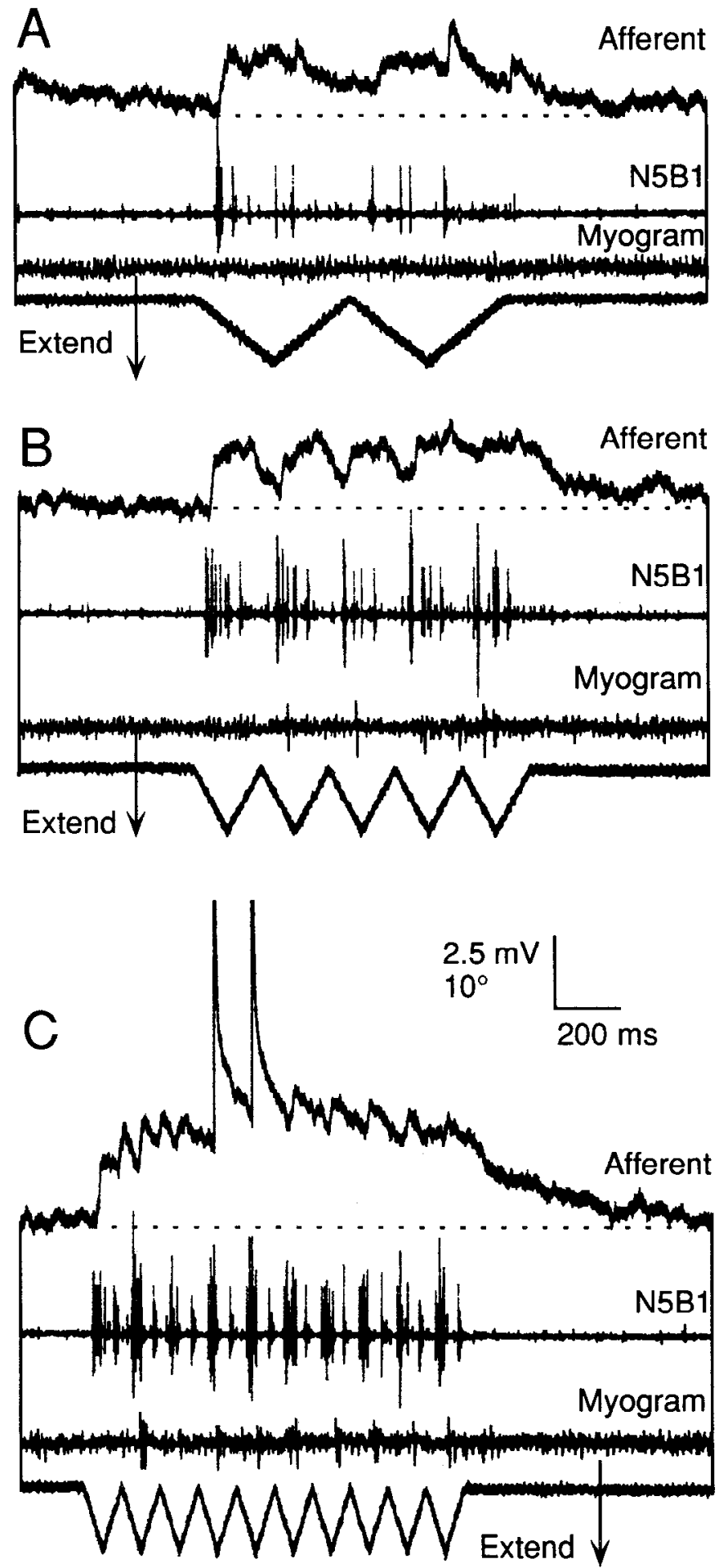

Figure 5. Synaptic inputs are present in velocity-sensitive afferents at all velocities of joint movements tested. $A-C$, An afferent was stimulated with repetitive movements of the apodeme at different velocities, from the same initial set position of the joint. $A$, At $2 \mathrm{~Hz}\left(40^{\circ} \mathrm{sec}^{-1}\right)$ only a synaptic input was evoked. Motor neurons were not excited, as indicated by the silent myogram from the extensor and flexor tibiae muscles. $B$, At $5 \mathrm{~Hz}\left(100^{\circ} \mathrm{sec}^{-1}\right)$ the synaptic input caused by each cycle of the movement summed. Flexor, but not extensor, motor spikes were evoked by some cycles of the movement, but always occurred after the onset of the inputs to the afferent. $C$, At $8.5 \mathrm{~Hz}\left(170^{\circ} \mathrm{sec}^{-1}\right)$ the synaptic input summed further and afferent spikes (peaks not shown) occurred in response to two cycles of the movement. This velocity was therefore close to the spike threshold for this afferent. The afferent was held hyperpolarized.
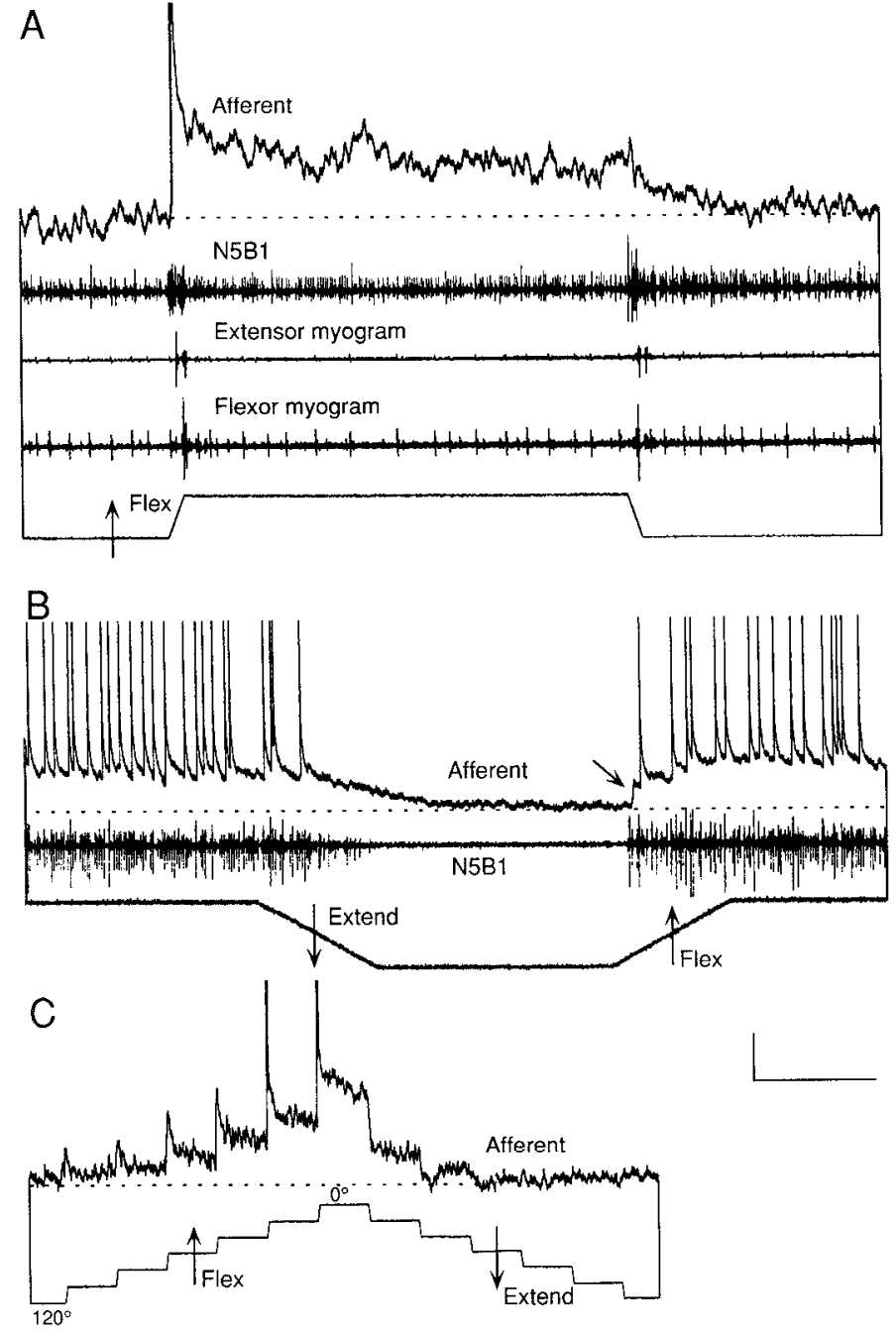

Figure 6. Sustained synaptic inputs to afferents. $A$, Movement of the apodeme to a more flexed position evoked a single spike in this velocitysensitive afferent, followed by a tonic synaptic input that was sustained for as long as the apodeme was held at this new position. This increased synaptic input was associated with an increase in the tonic spikes of other chordotonal afferents. Both the flexor and extensor motor neurons were excited phasically during the movements, but the tonic flexor spikes (also visible in the extensor myogram) showed no sustained change at the new position. $B$, An afferent that spiked tonically at a flexed position stopped spiking and its membrane repolarized when the tibia was extended. When the tibia was flexed again, a synaptic input depolarized the membrane before the spikes recommenced (arrow). $C, A$ phasic afferent that received a sustained and progressively larger tonic input at the more flexed angles, and a phasic input during each flexion movement. It spiked only at the more flexed positions of the joint. All three afferents were held hyperpolarized. Calibration: $A, 5 \mathrm{mV}, 10^{\circ}, 500$ $\mathrm{msec} ; B, 2.5 \mathrm{mV}, 10^{\circ}, 200 \mathrm{msec} ; C, 2 \mathrm{mV}, 2.5 \mathrm{sec}$.

For exanıle, a phasic flexion-sensitive afferent received a phasic synaptic input as the joint was flexed, and a sustained input at each new joint position (Fig. $6 \mathrm{C}$ ). As the joint was moved progressively to more flexed positions, both the phasic and sustained synaptic inputs became larger and spikes were now superimposed on these large depolarizations. The differences in the tonic synaptic inputs to the afferent at the same joint positions approached from opposite directions are probably caused by hysteresis of the overall chordotonal organ response (Zill, 1985a; Matheson, 1992b). 

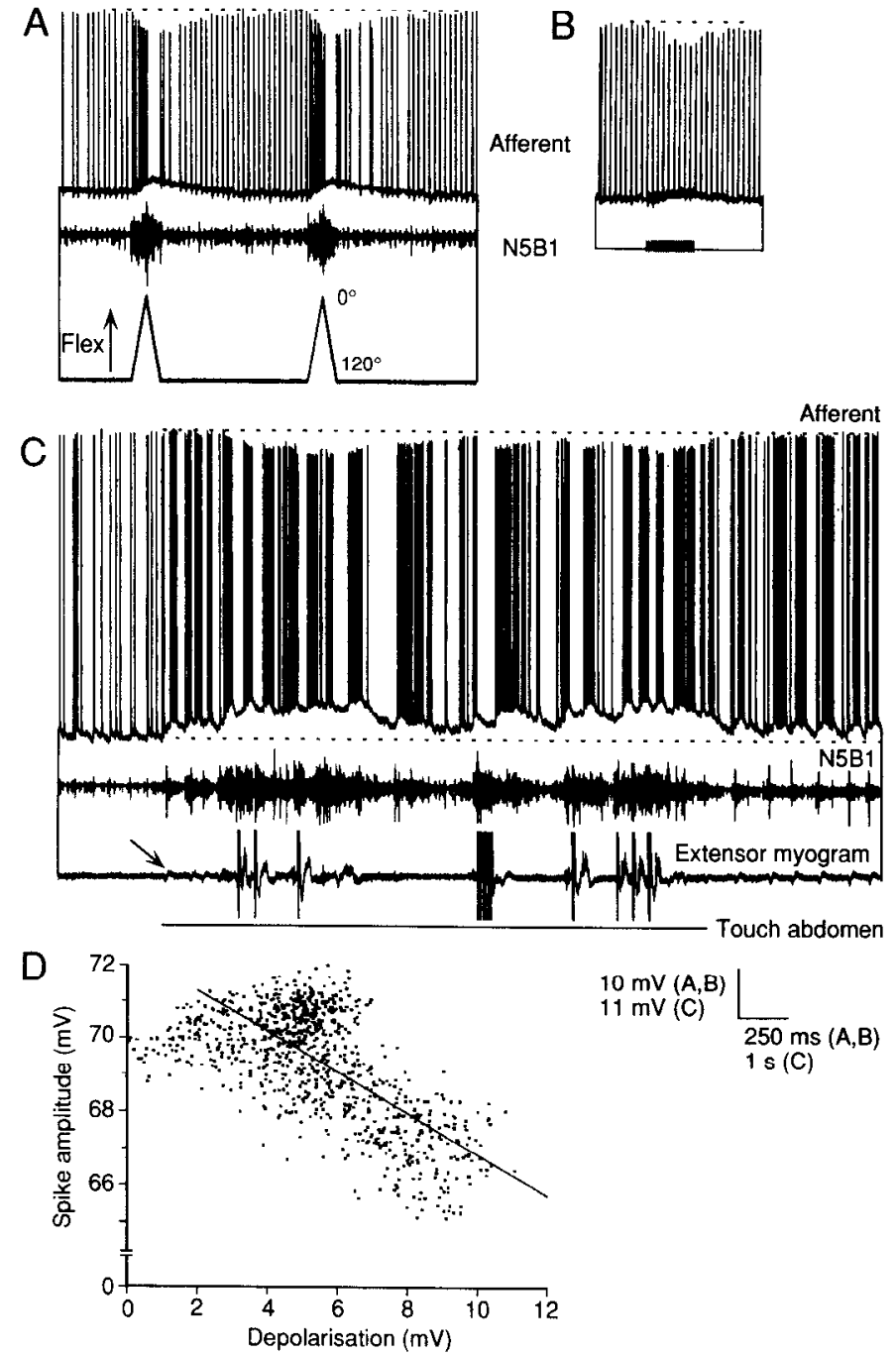

Figure 7. Synaptic inputs to an afferent reduce the amplitude of its spikes. $A, \mathrm{~A}$ flexion-sensitive afferent at its normal resting potential (upper trace) received a depolarizing synaptic input and spiked more rapidly during an imposed flexion. The synaptic inputs reduced the amplitude of the spikes. The recovery in the amplitude of the spikes paralleled the decline of the synaptic depolarization. $B$, Electrical stimulation of N5B 1 evoked synaptic potentials that reduced the amplitude of the tonic spikes in this same afferent without altering the spike frequency. $C$, Touching the abdomen of a different animal evoked contraction of the extensor (lower trace) and flexor muscles, which caused movements of the tibia that were then signaled by spikes of chordotonal afferents recorded extracellularly from N5B1 (middle trace). The spikes of a tonic afferent recorded intracellularly (upper trace) were increased in frequency and were superimposed on a synaptic input during the movements. When the afferent was depolarized by this input, the spikes were reduced in amplitude. The arrow indicates the first slow extensor motor spike. The larger spikes in the myogram are from the fast extensor motor neuron. The afferent was held slightly hyperpolarized. $D$, Graph of the relationship between the amplitude of synaptic depolarizations in the afferent shown in $C$ and the amplitude of its spikes (both are measured from the same baseline given the value $0 \mathrm{mV}$ ). A least-squares linear regression line calculated for the 854 data points shows that larger depolarizations cause larger reductions in spike amplitudes $(y=-0.56 x$ $+72.4, p<0.001$; coefficient of determination $=0.47$ ).

\section{Etfects of the synaptic input on spike amplitude}

The spikes of afferents recorded at normal membrane potential in the neuropil were reduced in amplitude when the afferent received synaptic inputs. For example, the tonically spiking af- ferent in Figure $7 \mathrm{~A}$ received a synaptic input during imposed movements of the apodeme. At the same time, its spikes were reduced in amplitude. In three animals where these measurements were made, this reduction ranged from $12 \%$ to $28 \%$. A similar reduction in amplitude was produced by evoking synaptic inputs in this afferent by electrical stimulation of the axons of other chordotonal afferents (Fig. $7 B$ ). The frequency of tonic spikes was unchanged by this stimulation but their amplitude was reduced by an average of $12 \%$. A clear reduction in the amplitude of the afferent spikes also occurred during evoked movements of the tibia of a different animal (Fig. 7C). These movements increased the spiking rate of the impaled afferent and some other chordotonal organ afferents. Synaptic inputs in the impaled afferent were correlated with the bursts of spikes in the other afferents and with a reduction in the amplitude of its own spikes. Plotting the amplitude of the synaptic inputs against the amplitude of the spikes revealed that this reduction was directly related to the amplitude of the depolarization caused by the synaptic input (Fig. $7 D$ ).

\section{Effects of the synaptic input on transmission to postsynaptic neurons}

The reduction in the amplitude of the spikes in the afferent terminals might alter their efficacy in releasing transmitter onto postsynaptic motor neurons. To test this possibility, simultaneous recordings were made from specific afferents that were presynaptic to a flexor tibiae motor neuron while the synaptic input to the afferent was manipulated by moving the apodeme of the chordotonal organ. Spikes in such an afferent were consistently followed at a constant latency of about $1 \mathrm{msec}$ by EPSPs in the motor neuron (Fig. $8 A-D$ ). These obscrvations arc consistent with those made by Burrows (1987) which indicate that connections between these afferents and motor neurons are direct and caused by the release of a chemical transmitter. When a spike of the impaled afferent occurred against a background of few spikes in other chordotonal afferents, it evoked an EPSP of $5 \mathrm{mV}$ in the postsynaptic flexor motor neuron (Fig. $8 A, B$ ). If the apodeme was then moved, a spike in the impaled afferent consistently produced an EPSP in the flexor of only $2 \mathrm{mV}$ in amplitude, representing a $60 \%$ reduction (Fig. $8 C, D$ ). The movement of the apodeme excited many other chordotonal afferents, and these led to a synaptic input to the impaled afferent on which its spikes were superimposed (Fig. $8 \mathrm{C}$ ). The flexor motor neuron was also initially depolarized by the imposed movement, but at the time when the impaled afferent spiked both the membrane potential and the pattern of synaptic inputs to the flexor had returned to the same levels as before the movement. The reduced efficacy of transmission is therefore caused by the synaptic input onto the presynaptic afferent and not by direct effects on the postsynaptic motor neuron.

Similar reductions in the efficacy of synaptic transmission were produced by depolarizing a tonically spiking afferent with a steady current (Fig. 8E). At its normal membrane potential this afferent evoked a $0.5 \mathrm{mV}$ EPSP as recorded in the cell body of a flexor motor neuron. When the spike was superimposed on a sustained depolarizing presynaptic current of $+1.5 \mathrm{nA}$, the EPSP was reduced to $0.3 \mathrm{mV}$. This current can be expected to change the membrane potential by $+5 \mathrm{mV}$, according to the known current/voltage relationships of the afferents (Burrows and Laurent, 1993). 


\section{Discussion}

Presynaptic inputs to afferent terminals

The central terminals of afferents from a chordotonal organ at the femorotibial joint of a locust hind leg receive many synaptic inputs during movements of this joint. These inputs are caused by chordotonal afferents excited by the same movements. The afferents also receive synaptic inputs from other sources, most notably elicited by mechanical stimulation of the other legs (T. Matheson and M. Burrows, unpublished observations). It is assumed that these inputs activate the same, or parallel sets of, interneurons as those excited by the chordotonal afferents. The results of this study are, however, concerned exclusively with the inputs from the chordotonal afferents. These synaptic inputs are associated with a conductance change in the membrane and a reduced excitability of the terminals that outlasts the conductance change (Burrows and Laurent, 1993). The depolarizing inputs result from summed IPSPs that have a reversal potential a few millivolts above resting potential (Burrows and Laurent, 1993). The summed inputs do not lead to antidromic spikes as do the inputs to crustacean mechanosensory afferents, which reverse some $15-40 \mathrm{mV}$ above resting potential (Cattaert et al., 1992). In the locust, both the pharmacology of the IPSPs, which indicates that they are mediated by GABA (Burrows and Laurent, 1993), and their physiology suggest that they are caused by interneurons. The synaptic input reduces the amplitude of the spikes in the ganglion, and this in turn is associated with a reduction in the amplitude of the EPSPs evoked in postsynaptic motor neurons. The net effect could contribute to changes in the gain of local reflexes initiated by the chordotonal organ, allowing their strength to be changed in different circumstances. This presynaptic inhibitory mechanism between afferents from a single sense organ represents a facet of mechanosensory processing that does not appear to have been described before.

\section{Interactions between afferents of the same or different modality}

The interactions between the cutaneous, muscle, and joint receptors from the limbs of vertebrates could alter the relative strengths of the afferent inputs to central neurons in different situations (see reviews by Schmidt, 1971; Rudomin, 1990a). Thus, the lateral inhibitory interactions between adjacent cutaneous afferents could enhance contrast and therefore increase localization of a stimulus (Schmidt, 1971). Similarly, the presynaptic interactions between the afferents from the two hairs on the cercus of a first instar cockroach could sharpen the directional sensitivity of their postsynaptic interneurons (Blagburn and Sattelle, 1987).

The interactions between vertebrate Ia afferents from different muscles could enhance the input to one set of motor neurons while decreasing that to other sets that are not required in a particular movement (Rudomin, 1990b). Similarly, information from proprioceptors on the legs of crayfish inhibits mechanosensory neurons sensitive to water movements, thereby reducing the input to sensory interneurons caused by voluntary leg movements (Fricke ct al., 1982). Sensory neurons from hairs on the cerci of locusts and cockroaches are modulated presynaptically by interneurons excited by inputs from a receptor that monitors movements of a cercus (Bernard, 1987; Boyan, 1988), and by nonsynaptic, mechanical effects (Goldstein and Camhi, 1988). These mechanisms, again, seem designed to prevent the hairs from initiating further responses during a voluntary movement.
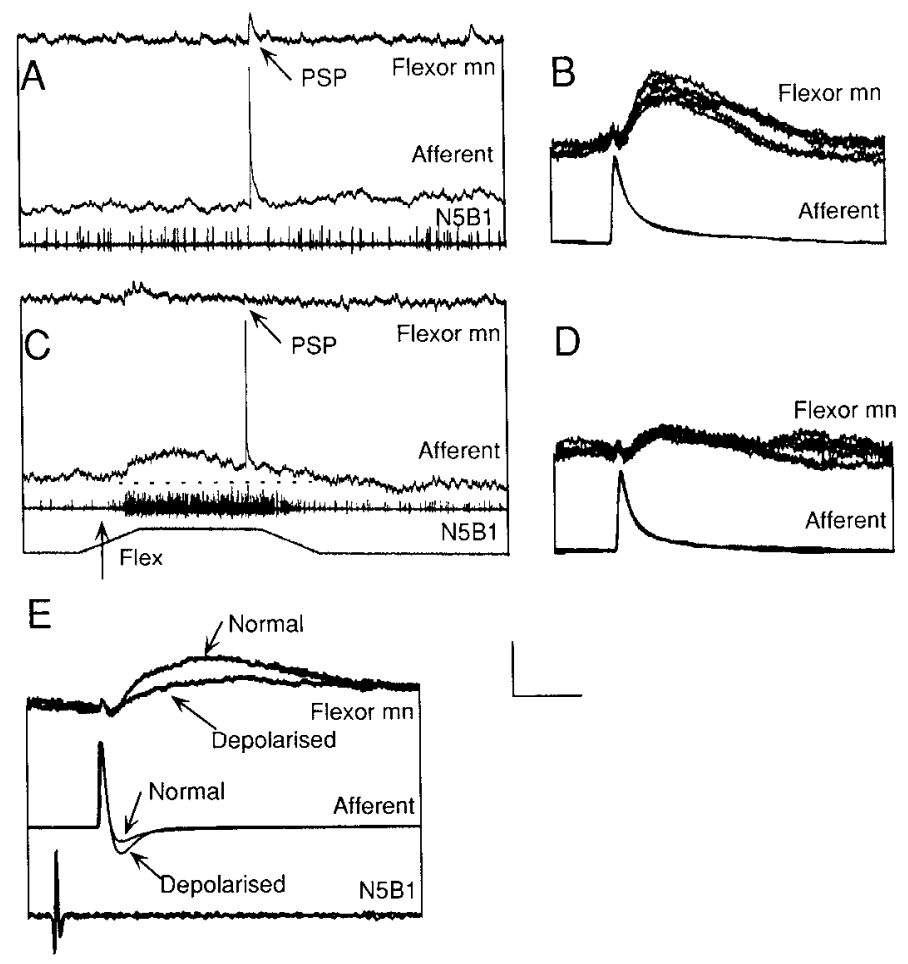

Figure 8 . Synaptic inputs reduce the effectiveness of the output synapses of an afferent. $A$, A spontaneously occurring spike in a phasic flexion-sensitive afferent (middle trace) was followed by a $5 \mathrm{mV}$ EPSP in a flexor motor neuron (upper trace). $B$, The EPSPs occurred consistently and with a constant latency. $C$, When the apodeme was flexed the afferent was depolarized and spiked once. The EPSP in the flexor was then reduced. $D$, The reduction in the amplitude of the EPSP was consistent. $E$, Another afferent that was presynaptic to a flexor motor neuron. At its normal membrane potential each afferent spike produced a $0.5 \mathrm{mV}$ EPSP in the flexor. Depolarizing current injected into this afferent reduced the amplitude of the EPSP to $0.3 \mathrm{mV}$. The peaks of the afferent spikes are not shown in $A$ and $C$. The afferent in $A-D$ was held slightly hyperpolarized. Calibration: $A$ and $C, 10 \mathrm{mV}, 500 \mathrm{msec}$, $10^{\circ} ; B$ and $D, 4 \mathrm{mV}$ (upper), $50 \mathrm{mV}$ (lower), $10 \mathrm{msec} ; E, 0.5 \mathrm{mV}$ (upper), $28 \mathrm{mV}$ (middle), $10 \mathrm{msec}$.

\section{Interactions between afferents from one organ}

Excluding the visual and auditory systems, we can find no other published examples of presynaptic inhibition between afferents from within a single sense organ. One related type of interaction is described for a crab thoracocoxal muscle receptor that is innervated by one spiking and two nonspiking mechanosensitive neurons. One of the nonspiking afferents makes an excitatory connection with the spiking neuron that extends the dynamic range of the postsynaptic afferent (Wildman and Cannone, 1991). By contrast, all locust chordotonal afferents appear to receive inhibitory synaptic inputs. The many different types of afferent response (Matheson, 1992a, gives 30), and the varied synaptic inputs to these afferents mean that the relationships between the two are complex. Nevertheless, the following general features emerge. First, the inputs may be phasic or tonic. Second, velocity-sensitive afferents may receive phasic inputs during all velocities of movements, including those to which they are most sensitive. For particular afferents this means that some movements evoke only a synaptic input, whereas the preferred movements evoke spikes superimposed on a synaptic input. Third, velocity-sensitive afferents may receive a tonic input that is dependent on the position of the joint. Fourth, 
tonic afferents may receive a phasic input during movements and a tonic input at particular positions of the joint. In all of these afferents, the synaptic inputs are generally more pronounced at the position, or during the movement to which the afferent is most sensitive. The inputs to many of these afferents must be caused by the convergence of information from many afferents with differing response properties. For example, the afferent in Figure $4 A$ received synaptic inputs during both flexion and extension movements, but no individual afferents give bursts of spikes in response to both directions of movement. A consequence of this convergence is that some movements or joint positions that do not cause an afferent to spike may nevertheless evoke synaptic inputs in that afferent. The function of these synaptic inputs is obscure. The inputs that occur when an afferent spikes place the transmission of information from this afferent to its postsynaptic motor neurons in the context of the summed activity of the many other chordotonal afferents that feed back onto it. The inputs to a given afferent must be mediated only by specific subsets of the other afferents, and not by all members of the population. They are highly specific for a particular afferent and do not occur during all movements or at all leg angles (see, e.g., Fig. 4C). The interactions between the afferents thus provide a mechanism by which the chordotonal organ can automatically regulate the gain of its own reflex effects. Moreover, the specificity of the inputs to different afferents means that their reflex effects can be changed with some degree of independence, giving a more subtle control of the overall gain.

\section{Afferent interactions and gain control mechanisms}

In the vertebrate cochlea, complex feedback systems mediate an automatic gain control mechanism that sharpens the tuning curves of auditory receptors (Lyon, 1991). The term "automatic gain control" is defined by Lyon as ". . . a mechanism for varying the sensitivity or gain of a system based on the signal level at the output of the system, so as to reduce the dynamic range of the output relative to the input." In the vertebrate visual system, automatic gain control sets the amount of light reaching the retina by adjusting the diameter of the pupil, and in the cortex limits the volume of information converging on higher-order neurons by acting on the summed, and probably weighted, output of groups of neurons (Bonds, 1991).

If the inhibitory inputs to locust chordotonal afferents were simply part of a lateral inhibitory mechanism responsible for sharpening the responses of the afferents, then the inputs should be strongest near the extremes of the afferents' operating ranges. Usually, however, the strongest inputs correspond with the maximal sensitivity of an afferent as defined by its frequency of spikes. This means that only the first spikes arriving at the CNS and signaling a change at the joint will be able to express their outputs at full gain. Spikes in other afferents that arrive later will be subjected to feedback inhibition from the faster afferents. Their output effects will therefore be reduced in a graded manner, depending on the number and response properties of the afferents that are activated at the same time. Furthermore, the feedback from position-sensitive afferents to velocity-and other position-sensitive afferents will ensure that a response is dependent on the starting position of the joint.

Such a gain control mechanism would prevent saturation of common postsynaptic target neurons when many afferents release transmitter simultaneously. It would also mean that the inhibition would be greater when more afferents are active, as during high-velocity movements. This feedback mechanism would explain why an experimentally applied depolarization of the soma of an afferent, which evokes spikes in only that afferent, generates large, recognizable EPSPs in motor neurons (Burrows, 1987). Conversely, when spikes of the same afferent are evoked by movements of the organ, other afferents are excited simultaneously and then only small EPSPs can be attributed to the individual afferent. This effect is also seen when an afferent spikes spontaneously in either the presence or absence of other afferent spikes (see Fig. 8).

These types of interactions may also explain, at least in part, the variable gain of the reflexes that are initiated by this proprioceptor (stick insect, Bässler, 1976; Kittmann, 1991; locust, Field and Burrows, 1982; Zill, 1985b; Zill and Jepson-Innes, 1990; crayfish, Cattaert et al., 1992). Kittmann (1991) showed that repetitive stimulation of a chordotonal organ in a stick insect caused a habituation of the resistance reflex gain over a period of many seconds. This time scale is orders of magnitude greater than that for the presynaptic mechanisms we describe, but this does not preclude a contribution of presynaptic inhibition to the habituation. The loop controlling the femorotibial joint in a stick insect is close to instability for high values of gain, and will oscillate if the mass of the tibia is altered (Bässler et al., 1974; Pfeiffer, 1989). Kittmann (1991) proposes that a reduction of gain will stabilize these oscillations.

Presynaptic inhibition between afferents could also alter the weighting of the parameters in the gain control loop, and may markedly affect the performance of the system (Prochazka, 1989). For example, as tibial velocity slows during a step cycle, positional information may become more important, and could assist targeting at the start and end of stance and swing phases. In the stick insect, for example, rapid movements of the chordotonal organ evoke an initial depolarization in extensor tibiae motor neurons, possibly caused by acceleration-sensitive afferents, followed by a hyperpolarization. Slower movements, however, produce only the hyperpolarization, caused indirectly by velocity-sensitive afferents (Bässler et al., 1986). If a gain control mechanism similar to the onc we propose were to operatc, then the acceleration-sensitive afferents with high conduction velocities (Hofmann and Koch, 1985) could excite the extensor motor neurons directly while presynaptically inhibiting the more slowly conducting velocity-sensitive afferents. Once the acceleration phase of the movement is over and the acceleration-sensitive afferents stop spiking, their direct effects on the motor neurons and their presynaptic inhibition of the velocity-sensitive afferents would decline. This would allow the effects of the velocitysensitive afferents to be expressed in full. Our results demonstrate that in the locust, such pathways do exist between the afferents monitoring the same movement, but to understand further the central control of these presynaptic effects, it is essential now to identify the interneurons implicated in these pathways.

\section{References}

Bässler U (1976) Reversal of a reflex to a single motoneurone in the stick insect Carausius morosus. Biol Cybern 24:47-49.

Bässler U, Cruse H, Pflüger H-J (1974) Der Regelkreis der Kniesehnenreflexes bei der Stabheuschrecke: Untersuchungen zur Stabilität des Systems im inaktiven Tier. Kybernetik 15:117-125.

Bässler U, Hofmann T, Schuch U (1986) Assisting components within a resistance reflex of the stick insect, Cuniculina impigra. Physiol Entomol 11:359-366. 
Bernard J (1987) Effectiveness of the cercal chordotonal inhibitory organ in the cockroach. Synaptic activity during imposed cercal movements. Comp Biochem Physiol [A] 87:53-56.

Blagburn JM, Sattelle DB (1987) Presynaptic depolarization mediates presynaptic inhibition at a synapse between an identified mechanosensory neurone and giant interneurone 3 in the first instar cockroach, Periplaneta americana. J Exp Biol 127:135-157.

Bonds AB (1991) Temporal dynamics of contrast gain in single cells of the cat striate cortex. Vis Neurosci 6:239-255.

Boyan GS (1988) Presynaptic inhibition of identified wind-sensitive afferents in the cercal system of the locust. J Neurosci 8:2748-2757.

Brogan RT, Pitman RM (1981) Axonal regeneration in an identified insect motoneurone. J Physiol (Lond) 319:34P-35P.

Burrows M (1987) Parallel processing of proprioceptive signals by spiking local interneurons and motor neurons in the locust. J Neurosci 7:1064-1080.

Burrows M, Laurent G (1993) Synaptic potentials in the central terminals of locust proprioceptive afferents generated by other afferents from the same sense organ. J Neurosci 13:808-819.

Burrows M, Laurent GJ, Field LH (1988) Proprioceptive inputs to nonspiking local interneurons contribute to local reflexes of a locust hindleg. J Neurosci 8:3085-3093.

Callec JJ (1974) Synaptic transmission in the central nervous system of insects. In: Insect neurobiology (Treherne JE, ed), pp 119-185. New York: Elsevier.

Cattaert D, El Manira A, Clarac F (1992) Direct evidence for presynaptic inhibitory mechanisms in crayfish sensory afferents. J Neurophysiol 67:610-624.

Davidoff RA (1972) GABA antagonism and presynaptic inhibition in the frog spinal cord. Science 175:331-333.

Eccles JC, Schmidt R, Willis WD (1963) Pharmacological studies on presynaptic inhibition. J Physiol (Lond) 168:500-530.

Field LH (1991) Mechanism for range fractionation in chordotonal organs of Locusta migratoria (L) and Valanga sp. (Orthoptera: Acrididae). J Insect Morphol Embryol 20:25-39.

Field LH, Burrows M (1982) Reflex effects of the femoral chordotonal organ upon leg motor neurones of the locust. J Exp Biol 101:265285.

Field LH, Rind FC (1981) A single insect chordotonal organ mediates inter- and intra-segmental leg reflexes. Comp Biochem Physiol [A] 68:99-102.

Frank K, Fuortes MGF (1957) Presynaptic and postsynaptic inhibition of monosynaptic reflexes. Fed Proc 16:39-40.

Fricke RA, Block GD, Kennedy D (1982) Inhibition of mechanosensory neurons in the crayfish. II. Inhibition associated with proprioceptive fecdback from locomotion. J Comp Physiol [ $\Lambda$ ] 149:251-262.

Goldstein RS, Camhi JM (1988) Modulation of activity in sensory neurons and wind-sensitive interneurons by cercal displacement in the cockroach. J Comp Physiol [A] 163:479-487.

Gossard J-P, Cabelguen J-M, Rossignol S (1990) Phase-dependent modulation of primary afferent depolarization in single cutaneous primary afferents evoked by peripheral stimulation during fictive locomotion in the cat. Brain Res 537:14-23.

Gussard J-P, Cabelguen J-M, Rossignol S (1991) An intracellular study of muscle primary afferents during fictive locomotion in the cat. $\mathrm{J}$ Neurophysiol 65:914-926.

Hofmann T, Koch UT (1985) Acceleration receptors in the femoral chordotonal organ in the stick insect Cuniculina impigra. J Exp Biol 114:225-237.

Hofmann T, Koch UT, Bässler U (1985) Physiology of the femoral chordotonal organ in the stick insect Cuniculina impigra. J Exp Biol 114:207-223

Hoyle G, Burrows M (1973) Neural mechanisms underlying behavior in the locust Schistocerca gregaria. I. Physiology of identified motorneurons in the metathoracic ganglia. J Neurobiol 4:3-41.

Hultborn H, Meunier S, Pierrot-Deseilligny E, Shando M (1987) Changes in presynaptic inhibition of Ia fibres at the onset of voluntary contraction in man. J Physiol (Lond) 389:757-772.

Janig W, Schmidt RF, Zimmermann M (1968) Two specific feedback pathways to the central afferent terminals of phasic and tonic mechanoreceptors. Exp Brain Res 6:116-129.

Jimenez I, Rudomin P, Solodkin M (1988) PAD patterns of physiologically identified afferent fibres from the medial gastrocnemius muscle. Exp Brain Res 71:643-657.
Kennedy D, Calabrese RL, Wine JJ (1974) Presynaptic inhibition: primary afferent depolarisation in crayfish neurons. Science 186:451454.

Kittmann R (1991) Gain control in the femur-tibia fecdback system of the stick insect. J Exp Biol 157:503-522.

Laurent G, Burrows M (1988) A population of ascending intersegmental interneurones in the locust with mechanosensory inputs from a hind leg. J Comp Neurol 275:1-12.

Laurent G, Burrows M (1989a) Distribution of intersegmental inputs to nonspiking local interneurones and motor neurones in the locust. J Neurosci 9:3019-3029.

Laurent G, Burrows M (1989b) Intersegmental interneurones can control the gain of reflexes in adjacent segments by their action on nonspiking local interneurones. J Neurosci 9:3030-3039.

Lyon RF (1991) Automatic gain control in cochlear mechanics. In: The mechanics and biophysics of hearing (Dallos P, Geisler CD, Matthews JW, Ruggero MA, Steele CR, eds), pp 395-402. New York: Springer.

Matheson T (1990) Responses and locations of neurones in the locust metathoracic femoral chordotonal organ. J Comp Physiol [A] 166: 915-927.

Matheson T (1992a) Morphology of the central projections of physiologically characterised neurones from the locust metathoracic femoral chordotonal organ. J Comp Physiol [A] 170:101-120.

Matheson T (1992b) Range fractionation in the locust metathoracic femoral chordotonal organ. J Comp Physiol [A] 170:509-520.

Matheson T, Ditz F (1991) A simple computer-controlled analogue ramp generator for producing multiple ramp-and-hold stimuli. J Neurosci Methods 39:45-52

Matheson T, Field LH (1990) Innervation of the metathoracic femoral chordotonal organ of Locusta migratoria. Cell Tissue Res 259:551560.

Nicoll RA, Alger BE (1979) Presynaptic inhibition: transmitter and ionic mechanisms. Int Rev Neurobiol 21:217-258.

Pfeiffer HJ (1989) Mass induced oscillations of the femur-tibia control system in the stick insect Carausius morosus. In: Brain - perception - cognition (Elsner N, Roth G, eds), p 52. Stuttgart: Thieme.

Prochazka A (1989) Sensorimotor gain control: a basic strategy of motor systems? Prog Neurobiol 33:281-307.

Rudomin P (1990a) Presynaptic control of synaptic effectiveness of muscle spindle and tendon organ afferents in the mammalian spinal cord. In: The segmental motor system (Binder MD, Mendell LM, eds), pp 349-380. New York: Oxford UP.

Rudomin P (1990b) Presynaptic inhibition of muscle spindle and tendon organ afferents in the mammalian spinal cord. Trends Neurosci 13:499-505.

Rudomin P, Jimenez I, Solodkin M, Duenas S (1983) Sites of action of segmental and descending control of transmission on pathways mediating PAD of Ia- and Ib-afferent fibers in cat spinal cord. J Neurophysiol 50:743-769.

Rudomin P, Solodkin M, Jimenez I (1986) PAD and PAH response patterns of group IA- and Ib-fibers to cutaneous and descending inputs in the cat spinal cord. J Neurophysiol 56:987-1006.

Sattelle DB, Breer H (1990) Cholinergic nerve terminals in the central nervous system of insects. J Neuroendocrinol 2:241-256.

Schmidt RF (1971) Presynaptic inhibition in the vertebrate central nervous system. Ergeb Physiol 63:20-101.

Shelton PMJ, Stephen RO, Scott JJA, Tindall AR (1992) The apodeme complex of the femoral chordotonal organ in the metathoracic leg of the locust Schistocerca gregaria. J Exp Biol 163:345-358.

Skorupski P, Sillar KT (1986) Phase-dependent reversal of reflexes mediated by the thoracocoxal muscle receptor organ in the crayfish, Pacifastacus leniusculus. J Neurophysiol 55:689-695.

Small SA, Kandel ER, Hawkins RD (1989) Activity-dependent enhancement of presynaptic inhibition in Aplysia sensory neurons. Science 243:1603-1606.

Usherwood PNR, Runion HI, Campbell JI (1968) Structure and physiology of a chordotonal organ in the locust leg. J Exp Biol 48:305323.

Watson AHD, Burrows M, Leitch B (1993) GABA-immunoreactivity in processes presynaptic to the terminals of afferents from a locust leg proprioceptor. J Neurocytol 22:547-557.

Wildman MH, Cannone AJ (1991) Interaction between afferent neurones in a crab muscle receptor organ. Brain Res 565:175-178.

Zill SN (1985a) Plasticity and proprioception in the insects. I. Re- 
sponses and cellular properties of individual receptors of the locust metathoracic femoral chordotonal organ. J Exp Biol 116:435-461.

Zill SN (1985b) Plasticity and proprioception in the insects. II. Modes of reflex action of the locust metathoracic femoral chordotonal organ. J Exp Biol 116:463-480.
Zill SN, Jepson-Innes K (1990) Functions of a proprioceptive sense organ in freely moving insects-characteristics of reflexes elicited by stimulation of the locust metathoracic femoral chordotonal organ. Brain Res 523:211-218. 